\title{
Food insecurity and psychological distress in Invit adolescents of Nunavik
}

\author{
Maude Bradette-Laplante ${ }^{1}$, Yohann Courtemanche ${ }^{1}$, Mireille Desrochers-Couture', \\ Nadine Forget-Dubois ${ }^{1}$, Richard E Bélanger ${ }^{1,2}$, Pierre Ayotte ${ }^{1,3,4}$, Joseph L Jacobson ${ }^{5}$, \\ Sandra W Jacobson ${ }^{5}$ and Gina Muckle ${ }^{1,6, *}$ \\ ${ }^{1}$ Centre de Recherche du Centre Hospitalier Universitaire de Québec-Université Laval, Québec, Canada: \\ ${ }^{2}$ Département de Pédiatrie, Université Laval, Québec, Canada: ${ }^{3}$ Centre de Toxicologie du Québec, Institut National de \\ Santé Publique du Québec, Québec, Canada: ${ }^{4}$ Département de Médecine Sociale et Préventive, Université Laval, \\ Québec, Canada: ${ }^{5}$ Department of Psychiatry and Behavioral Neurosciences, Wayne State University School of \\ Medicine, Detroit, MI, USA: 'École de Psychologie, Université Laval, Québec GIV OA6, Canada
}

Submitted 28 March 2019: Final revision received 19 December 2019: Accepted 6 January 2020: First published online 27 May 2020

\begin{abstract}
Objective: The present study aims at measuring the association between household food insecurity and psychological distress in adolescents in Inuit communities, concurrently and overtime from childhood to adolescence.

Design: The study used measures of internalising behaviours (anxiety, withdrawn attitude, somatic complaints and depression) as indicators of psychological distress during adolescence, a concurrent measure of household food insecurity in adolescence and an assessment of longitudinal patterns of household food insecurity from childhood to adolescence. We collected descriptive information at birth, childhood and adolescence on potential confounders.

Setting: Inuit communities of Nunavik in northern Quebec, Canada

Participants: The study consisted of 212 participants from the Nunavik Child Development Study, who have been assessed at birth, childhood (mean age $=11$ years, range $=9-13$ years) and adolescence (mean age $=18$ years, range $=16-21$ years).

Results: Concurrent severe household food insecurity in adolescence was associated with higher measures of psychological distress: depression $\left(\beta_{\text {std }}=0.26, P<0.01\right)$ and withdrawn attitude $\left(\beta_{\text {std }}=0 \cdot 20, P=0.04\right)$. Persistent household food insecurity (both at childhood and adolescence) was associated with higher levels of adolescent depression $\left(\beta_{\text {std }}=0 \cdot 18, P=0.02\right)$ and anxiety $\left(\beta_{\text {std }}=0.17, P=0.03\right)$.

Conclusions: Adolescents from Nunavik living with higher food insecurity and those having experienced food insecurity in both childhood and adolescence were more likely to report symptoms of psychological distress. Considering the high level of distress experienced by young Inuit, existing initiatives to reduce food insecurity in Nunavik communities should be targeted to include children and adolescents.
\end{abstract}

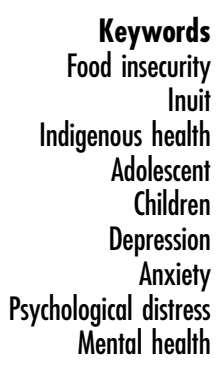

Food security is defined as people having physical and economic access to sufficient, safe and nutritious food to meet their dietary needs and food preferences at all times for an active and healthy life ${ }^{(1)}$. In Canada, according to a 2012 report, $13 \%$ of households experienced some level of food insecurity, whereas in Inuit communities, this proportion reached $52 \%{ }^{(2)}$.

Northern Native communities of Quebec historically relied entirely on the land and sea to obtain their food. Food sources consisted mainly of land mammals, marine mammals, fish, birds (geese, ptarmigan) and berries, now referred to as 'traditional foods'. In this particular population, food access depends on skills and opportunities and can be influenced by climate changes and availability of the resources. Participation in traditional activities and 'going on the land' are important features of cultural identity and well-being ${ }^{(3)}$. Conversely, frequent consumption of local country food contributes to contaminants exposures, such as $\mathrm{Hg}$, and nutrient intake, such as $n-3$ fatty acids ${ }^{(4)}$. In the last century, with the settlement and Westernisation of 
the communities, Inuit faced major changes in their eating habits as well as in many other aspects of their life ${ }^{(5)}$. This fast, drastic transition meant going from a diet consisting only of country food to mainly store-bought food; although country foods are still regularly consumed, market foods now represent a greater proportion of the diet for most Inuit in Nunavik ${ }^{(5,6)}$.

The Nunavik region is located in the Arctic region of the Province of Quebec in Canada, beyond the 55th parallel north. The region being remote from the rest of the province, store-bought food has to be shipped using boats and planes, which impacts its quality, access and price. The cost of market food is almost twice the price found in other areas of the province ${ }^{(7)}$, and Nunavik inhabitants now have to depend on an income or subsidy to obtain food from the grocery store. Acquiring country food now also depends on access to transportation, supplies and gasoline and thus requires financial means ${ }^{(8,9)}$. Median income for Inuit of Nunavik aged 15 years and over is only $32 \%$ of the income of the non-Indigenous inhabitants of the region $^{(8)}$. As a result, access to sufficient and nutritious food can be compromised in the Inuit population.

Studies of Canadian Inuit communities have demonstrated that food insecurity is related to decreased diet quality and nutrient intake; food insecurity has also been shown to affect the physical health of children, notably their growth and their risk of anaemia ${ }^{(10-13)}$. Although not yet documented in the Inuit population, high levels of food insecurity are associated with poor mental health in children, adolescents and adults in Western populations ${ }^{(14,15)}$. Potential mental health issues include internalising behaviours, which are emotional problems directed inwards; in childhood and adolescence, they include symptoms of psychological distress (depression symptoms, anxiety symptoms, somatic complaints and teenage suicide $)^{(16)}$. In children, associations between food insecurity and psychological distress have been widely investigated, showing that children experiencing higher levels of food insecurity are more likely to suffer from symptoms of distress, such as anxiety and depression ${ }^{(17,18)}$. In adolescents, higher food insecurity is associated with a greater risk of mental health symptoms or disorders, including anxiety symptoms $^{(19,20)}$. The association between household food insecurity and psychological distress can be long-lasting, with late childhood ( $\approx 12$ years of age) food insecurity associated with depression and anxiety symptoms later in adolescence $(\approx 16-18 \text { years of age })^{(21)}$. Unfortunately, in low-income households in urban areas, adolescents are twice as burdened by food insecurity compared with younger children.

The effect of food insecurity on psychological distress in adolescence is a growing concern; yet little is known about how Inuit adolescents are exposed and affected by the high levels of food insecurity in their communities. The Inuit population of Nunavik is largely composed of young people, with $58 \%$ of its inhabitants aged 25 years or less in
2011 , whereas the proportion of young people was $16 \%$ in the non-Aboriginal populations of Canada ${ }^{(22)}$. Moreover, psychological distress, such as depression and the rate of suicide, is higher in Inuit communities compared with the general Canadian population, with a suicide rate ten times higher in Nunavik than the rest of Canada ${ }^{(8,23)}$.

Considering the scope of these issues, the present study aims to assess the association between food insecurity and psychological distress during adolescence in Inuit communities and to examine whether the burden of persistent household food insecurity overtime from childhood to adolescence is associated with psychological distress during adolescence.

\section{Methods}

\section{Participants}

The participants were members of an ongoing motherchild prospective longitudinal cohort. First, mothers from the Nunavik region were recruited for the Cord Blood Monitoring Program, which aimed at measuring prenatal nutrient profile and environmental contaminants ${ }^{(24)}$. The recruitment period extended from November 1993 to December 1996 ( $n 491$ mothers). During a subsequent project, the US National Institutes of Health infancy study that took place between November 1995 and March 2002, 221 more mothers were recruited ${ }^{(25,26)}$.

At school age (9-13 years), a subsample of these children and their primary caregiver (PC) ( $n$ 294: 247 from the Cord Blood Monitoring Program and forty-seven from the National Institute of Health infancy study) participated in the Nunavik Child Development Study (NCDSchildhood), a follow-up designed to examine effects of pre- and postnatal exposure to environmental contaminants on child behaviour and cognitive abilities, which took place between September 2005 and February 2010 ${ }^{(27)}$. Participant interviews and assessments took place in the three main villages of Nunavik. Participants from other villages were transported by plane to the nearest assessment site. Details of the recruitment procedures for the Cord Blood Monitoring Program and NCDS-childhood have been reported in previous publications ${ }^{(24,28)}$.

The participants were evaluated again during adolescence (NCDS-adolescence) between January 2013 and February 2016 (16-21 years). Inclusion criteria for the NCDS-adolescence follow-up were participation in both prenatal and childhood study and currently residing in Nunavik. Those who were identified as suffering from severe health or neurological problems unrelated to exposure at the NCDS-childhood interview (epilepsy $n$ 2; head trauma $n 1$; meningitis $n 1$; multiple sclerosis $n$ 1) were excluded from the NCDS-adolescence follow-up. Some children of the NCDS-childhood study were excluded ( $n$ 49) because they could not be reached, had moved away or were hospitalised ( $n$ 28), twelve were 


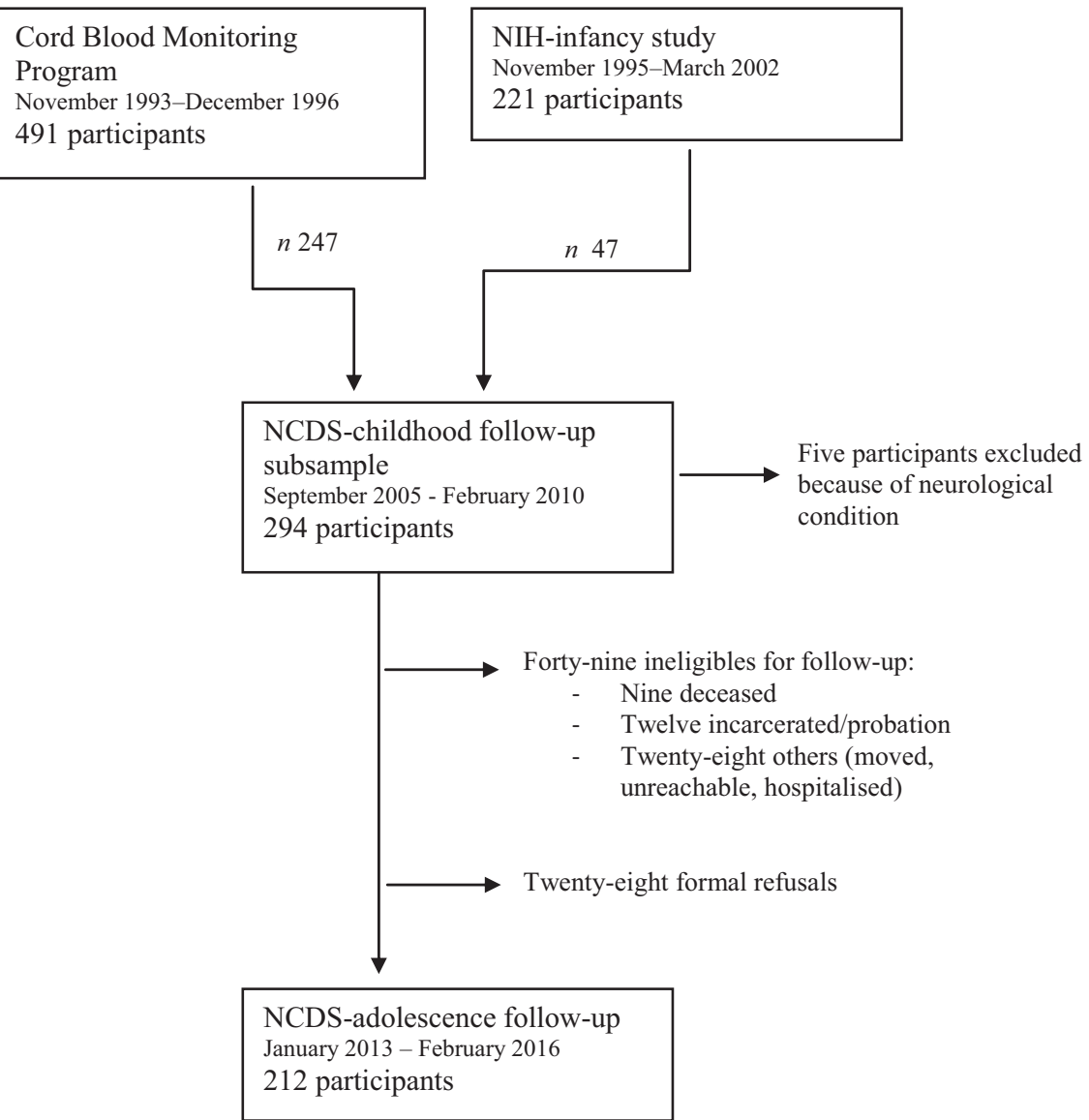

Fig. 1 Flow chart for recruitment and follow-up of study participants from November 1993 to February 2016 including reasons and number of excluded participants through follow-ups. NIH, National Institutes of Health; NCDS, Nunavik Child Development Study

incarcerated, nine had died and twenty-eight declined. A total of 212 adolescents were included in the follow-up NCDS-adolescence study and transported by plane to one of the three largest villages of Nunavik, where they met with the research team in one of the three largest villages of Nunavik (Fig. 1). Adolescents were given an electronic music device worth $\$ 50$ USD as a compensation for their participation.

At recruitment, written informed consent was obtained from the mothers. For NCDS-childhood, PC provided written consent and children provided verbal consent, whereas in NCDS-adolescence, participants gave their own written consent.

Baseline characteristics were compared between participants not included in subsequent visits or lost to follow-up ( $n$ 501) and those followed until adolescence ( $n$ 212) by $\chi^{2}$ and Wilcoxon tests. At birth, girls and boys were equally represented in the sample ( $49 \% v .51 \%$, respectively), but girls were more likely than boys to be followed through adolescence ( $56 \%$ of girls $v$. $44 \%$ of boys, $P=0.02$ ). There were no differences in terms of maternal age, parity at delivery, birth weight or cord blood concentrations $(\mathrm{Hg}$, $\mathrm{Pb}$ and $\mathrm{DHA})$.

\section{Adolescent psychological distress assessment}

The Child Behavior Checklist (CBCL) from the Achenbach System of Empirically Based Assessments was used to measure internalising behaviour during adolescence ${ }^{(29)}$. The Youth Self-Report questionnaire was completed with each participant during an interview, which is recommended for children aged 11 years and older and consists of 112 items scored on a three-point Likert scale $(0=$ not true, $1=$ somewhat or sometimes true, $2=$ very true or often true). The questionnaire yields scores on eight derived syndrome scales. Here, we only report the internalising problems scale, which is a combination of three subscales: anxious/ depressed score, withdrawn/depressed score and somatic complaints score. We used continuous scores from each subscale as well as the total internalising problems score in all analyses. Although the Youth Self-Report had never been used before with an Inuit population, it has been formerly used in various cultural contexts including other young Indigenous people in the $\operatorname{Arctic}^{(30,31)}$. The internal consistency of the internalising scale was high $\left(\alpha_{\text {ordinal }}=0.90\right)$ and adequate for the different subscales (anxious $/$ depressed $\alpha_{\text {ordinal }}=0.84$, withdrawn $/$ depressed $\alpha_{\text {ordinal }}=0.74$ and somatic complaints $\alpha_{\text {ordinal }}=0.75$ ). 
The short form of the Center for Epidemiological Studies-Depression (CES-D) scale was used to document symptoms associated with depression, such as restless sleep, poor appetite and feeling lonely ${ }^{(32)}$. Participants had to rate each of the ten items, indicating how frequently over the past week they experienced symptoms related to depression, with answers rated on a four-point Likert scale ranging from 0 (rarely) to 3 (all the time). A continuous score, indicating the level of depression symptoms, was used in all analyses. The CES-D tool has been validated in a North American Indigenous population ${ }^{(33)}$. We computed internal consistency for the scale, which was found to be adequate $\left(\alpha_{\text {ordinal }}=0.73\right)$.

\section{Food insecurity assessment}

Household food insecurity was assessed at both the childhood and adolescent follow-up visits. Questions on food insecurity in the household were answered by the PC at the childhood follow-up and by the participants themselves at the adolescent follow-up. A self-reported measure of household food insecurity by adolescents was chosen because many adolescents in Nunavik spend a lot of time outside of their household (visiting family/friends, started their own family) and parents may therefore not be able to accurately report food insecurity.

\section{Childhood assessment}

Household food insecurity during childhood was previously established by our group based on three questions included in a PC interview: (1) Could you please describe the amount eaten by your family (enough/not enough)? (2) Do adults in your family have to cut down on the size of meals because there is not enough money (yes/no)? (3) Do children in your family have to cut down on the size of meals because there is not enough money (yes/no)? The food insecurity variable used in the childhood assessment was dichotomous; a positive answer to any of the items indicated the presence of food insecurity.

\section{Adolescent assessment}

Food insecurity level in adolescence was measured using a modified version of the US Food Security Survey Module $^{(34)}$. Questions used in this study were adapted to the Indigenous cultural context by the Nutrition and Food Security in Kugaaruk Survey, Nunavut ${ }^{(35)}$. Since adolescent participants may live in a household without any children, all questions targeting households with children were withdrawn. The eight questions included in this survey covered whether the household could afford the food needed, whether the household could afford healthy meals, whether household members had to cut the size of meals or if they went hungry (modified instrument presented in online supplementary material). The scoring method from Health Canada was used to consider income-related household food security ${ }^{(36)}$. This household food insecurity score (range 0-10) was used to create a three-category measure of food insecurity in the household: food security (score $<2)$, moderate food insecurity $(2 \leq$ score $<6$ ) and severe food insecurity (score $\geq 6$ ).

\section{Longitudinal patterns}

Patterns of food insecurity from childhood to adolescence were computed using food insecurity status at both follow-ups. For comparison purposes, we created a dichotomous score for the adolescence food insecurity status from the three-category measure. Adolescent food secure households and moderate food insecure households were combined as low-risk households, while severe food insecure households remained as those at higher risk of food insecurity. Four food insecurity patterns were created: persistent food security (food security at both childhood and adolescence measurement times), food insecurity in childhood to food security in adolescence, food security in childhood to food insecurity in adolescence and persistent food insecurity. For analysis purposes, persistent food security was used as a baseline for all other patterns.

\section{Confounding variables}

Confounding variables were selected from a list of possible variables related to both food insecurity (predictor) and psychological distress (outcome) based on existing studies: (1) maternal characteristics: age at delivery and socioeconomic status (SES) at childhood follow-up; (2) birth/ childhood characteristics: sex, birth weight, gestational age at birth, cord blood concentrations of $\mathrm{Hg}, \mathrm{Pb}$ and PCB 153 (polychlorinated biphenyl), breast-feeding duration and adoption status; (3) adolescent characteristics: age, SES, adolescent having a living child, marital status, perception of household crowding, education level, employment status, smoking status, general physical health and blood concentrations of $\mathrm{Hg}, \mathrm{Pb}, \mathrm{PCB} 153$, Hb and ferritin. These variables were first retained if associated with both predictor and outcome at $P<0 \cdot 20$. From this preliminary selection, we entered the potential confounders in each model in decreasing order of association with the outcome and retained them if they altered the association between predictor and outcome by at least $10 \%{ }^{(37)}$. Age and sex of the adolescent were mandatory confounding variables included in all analyses (model 1 and model 2). Adolescent SES was a mandatory confounding variable in model 2 for all outcomes. Additional confounding variables retained for cross-sectional analyses in adolescence were participant perception of household crowding, selfperceived general health (from the Youth questionnaire of First Nations Regional Health Survey of 2009), adolescent having a living child, cord blood Hg concentrations, cord blood concentrations of DHA and adolescent tobacco smoking. For longitudinal analyses, retained confounding variables were cord blood $\mathrm{Pb}$ concentrations, cord blood DHA concentrations, parity of the mother at birth of the participant, household crowding in childhood, maternal 
evaluation of child's health in childhood, PC marital status in childhood, child blood $\mathrm{Pb}$ level, child blood $\mathrm{Hg}$ level, adolescent perception of household crowding, self-perceived general health in adolescence, adolescent tobacco smoking and adolescent participant having a living child.

\section{Statistical analyses}

Bivariate associations between outcomes were tested using Pearson correlations. Following the covariate selection process described above, we investigated the association between food insecurity and psychological distress using multivariate linear regression.

\section{Assumptions}

Normality was visually verified for all continuous variable distributions; cord and child blood $\mathrm{Hg}$ concentrations and child blood $\mathrm{Pb}$ concentrations were $\log _{2}$-transformed to reduce skewness. The variance-covariance matrix was verified for collinearity.

The measures with the largest proportion of missing data were adolescent tobacco use $(5.6 \%, n 12)$, whether the adolescent had a child $(5.6 \%, n 12)$, and adolescent food security status $(5 \cdot 2 \%, n$ 11). Little's missing completely at random test indicated no systematic bias arising from missingness $\left(\chi^{2}=794 \cdot 10, \mathrm{df}=847, P=0.76\right)^{(38)}$.

Descriptive statistics and Pearson correlations were computed with the SAS 9.4 software. Internal consistency of the CBCL and CES-D was computed using the MPlus 8.2 software. The mcartest SAS macro was used to perform missing data pattern analysis and test the missing completely at random assumption. Final regression models were computed with the CALIS procedure in SAS using the full information maximum likelihood estimator. The threshold of significance was established at $P<0.05$. The full information maximum likelihood estimator allowed use of all available information, even if some values were missing for some participants. The assumption of missing at random (for full information maximum likelihood) was met since our data were considered missing completely at random based on Little's missing completely at random test ${ }^{(39)}$.

\section{Results}

\section{Sample characteristics}

Descriptive characteristics of the sample are presented in Table 1. In childhood, participants ranged from 9 to 13 years of age $($ mean $=11.3)$ and $49.5 \%$ were from food insecure household. Adolescents in the study ranged from 16 to 21 years $($ mean $=18 \cdot 5)$. When considering household food security in adolescence in three categories, $18.4 \%$ of the adolescents were food secure, $43.8 \%$ were moderately food insecure and $37.8 \%$ were severely food insecure. From childhood to adolescence, $38.7 \%$ were in the persistent household food security pattern, compared with $37.2 \%$ in an unstable household food insecurity pattern, either insecure in childhood and food secure in adolescence or vice versa, and $24.1 \%$ were in food insecure households at both times. Correlations between outcome variables are reported in Table 2 .

\section{Associations between adolescent bousebold food insecurity and psychological distress}

Table 3 presents baseline and fully adjusted regression models (model 1 and model 2) with the three-category score of household food insecurity at adolescence as the predictor of psychological distress.

Using food secure households as the reference group, linear regression analyses showed that moderately food insecure households were not significantly associated with any of CBCL subscale scores or the CES-D score. However, belonging to the severe food insecurity group was significantly related to the higher CBCL withdrawn/depressed score, related to greater overall CBCL internalising behaviour score in the model 1 (and marginally in model 2, $P=0.07)$ and marginally related to the anxious/depressed score, but not to the somatic complaints score for both models. Thus, adolescents in the severe food insecurity had on average 1.24 more symptoms on the CBCL withdrawn/depressed score compared with adolescents in the food security group. Adolescents in the severe food insecurity group also had higher CES-D depression scores, with on average $2 \cdot 24$ more symptoms on CES-D score than adolescents in the food security group.

\section{Associations between patterns of food insecurity from childhood to adolescence and adolescent psychological distress}

Table 4 illustrates the baseline and fully adjusted regression models (model 1 and model 2) of the three household food insecurity patterns that were compared with the persistent household food security pattern. None of the unstable patterns, namely from food secure households in childhood to food insecure households in adolescence or from food insecure households in childhood to food secure households in adolescence, showed any association with psychological distress indicators. By contrast, the persistent household food insecurity pattern was associated with higher scores on the CBCL internalising, anxious/depressed and withdrawn/depressed as well as on the CES-D depression scales in model 1 . These significant associations persisted in the fully adjusted regression models (model 2) for the CBCL anxious/depressed and the CES-D depression scales. There was no longitudinal association between household food insecurity documented during childhood and psychological distress outcomes in adolescence (results not shown). 
Table 1 Sample characteristics of the participants at birth, childhood and adolescence

\begin{tabular}{|c|c|c|c|c|c|c|}
\hline Variables & $n$ & Mean & $n$ & $\%$ & SD & Range \\
\hline \multicolumn{7}{|l|}{ Birth/family at birth characteristics } \\
\hline Child sex (\% girls) & 212 & & 118 & $55 \cdot 66$ & - & \\
\hline Parity of the mother including present child & 212 & 2.97 & & & 1.79 & $1.00-9 \cdot 00$ \\
\hline Cord blood DHA concentration (\% phospholipids) & 203 & $3 \cdot 60$ & & & 1.29 & $1.12-7.73$ \\
\hline Cord blood $\mathrm{Pb}$, geomean $\pm \mathrm{GSD}(\mu \mathrm{g} / \mathrm{dl})$ & 204 & $3 \cdot 80$ & & & 1.84 & $0.83-17.80$ \\
\hline Cord blood Hg, geomean \pm GSD ( $\mu \mathrm{g} / \mathrm{dl})$ & 204 & 1.52 & & & $2 \cdot 15$ & $0.18-9.93$ \\
\hline \multicolumn{7}{|l|}{ Childhood/family characteristics } \\
\hline Age (years) & 212 & $11 \cdot 34$ & & & 0.71 & $9 \cdot 32-13.97$ \\
\hline SES score* & 212 & 28.59 & & & 11.38 & $8.00-66.00$ \\
\hline Blood Hg, geomean \pm GSD $(\mu \mathrm{g} / \mathrm{dl})$ & 210 & 3.36 & & & 2.56 & $0.05-28.02$ \\
\hline House crowding (\% yes) $\dagger$ & 210 & & 171 & 81.43 & - & \\
\hline $\mathrm{PC}$ marital status at childhood & 210 & & & & & \\
\hline Married & & & 91 & $43 \cdot 13$ & - & \\
\hline Living with someone as a couple & & & 65 & 30.81 & - & \\
\hline Single & & & 27 & $12 \cdot 80$ & - & \\
\hline Divorced/separated & & & 24 & 11.37 & - & \\
\hline Widower & & & 4 & 1.90 & - & \\
\hline Maternal evaluation of child's health $\ddagger$ & 209 & & & & & \\
\hline Excellent & & & 79 & 37.80 & - & - \\
\hline Good & & & 113 & 54.07 & - & - \\
\hline Fair & & & 16 & 7.66 & - & - \\
\hline Poor & & & 1 & 0.48 & - & - \\
\hline Household food insecurity (\% yes)§ & 210 & & 104 & 49.52 & - & \\
\hline \multicolumn{7}{|l|}{ Adolescent characteristics } \\
\hline Age (years) & 212 & 18.47 & & & $1 \cdot 11$ & $16 \cdot 01-21 \cdot 88$ \\
\hline SES score (principal provider) ${ }^{\star}$ & 207 & 28.59 & & & 13.01 & $8.00-61.00$ \\
\hline Tobacco smoking ( $\%$ yes last 12 months) & 200 & 176 & & 88.00 & - & - \\
\hline Adolescent perception of house crowding (\% yes) & 202 & 44 & & 21.78 & - & - \\
\hline Adolescent having a living child (\% yes) & 200 & 40 & & 20.00 & _- & - \\
\hline Self-perceived general health $\ddagger$ & 209 & & & & & \\
\hline Excellent & & 12 & & 5.74 & - & - \\
\hline Very good & & 30 & & 14.35 & - & - \\
\hline Good & & 134 & & 64.11 & - & - \\
\hline Fair & & 25 & & 11.96 & - & - \\
\hline Poor & & 8 & & 3.83 & - & - \\
\hline Education level & 210 & & & & & \\
\hline Secondary 1 or less & & & 46 & 21.90 & - & - \\
\hline Secondary 2 or 3 & & & 105 & $50 \cdot 00$ & - & - \\
\hline Secondary 4 or higher & & & 59 & $28 \cdot 10$ & - & - \\
\hline Occupational status & 210 & & & & & \\
\hline Working & & & 75 & 35.71 & - & - \\
\hline School & & & 34 & $16 \cdot 19$ & - & - \\
\hline Both & & & 37 & 17.62 & - & - \\
\hline None & & & 64 & $30 \cdot 48$ & & - \\
\hline Household food security in three categories (\% yes)\| & 201 & & & & & \\
\hline Food secure & & & 37 & 18.41 & - & - \\
\hline Moderately food insecure & & & 88 & 43.78 & - & - \\
\hline Severely food insecure & & & 76 & 37.81 & - & - \\
\hline Household food security paths (childhood to adolescence) & 199 & & & & & \\
\hline Food secure persistent & & & 77 & 38.69 & - & - \\
\hline Food insecure $\rightarrow$ Food secure & & & 48 & 24.12 & - & - \\
\hline Food secure $\rightarrow$ food insecure & & & 26 & 13.07 & _- & _ \\
\hline Food insecure persistent & & & 48 & 24.12 & - & - \\
\hline \multicolumn{7}{|l|}{ Behaviours } \\
\hline CBCL - internalising & 210 & $15 \cdot 65$ & & & 8.03 & $2 \cdot 00-42 \cdot 00$ \\
\hline $\mathrm{CBCL}$ - withdrawn/depressed & 210 & 6.06 & & & 3.03 & $0.00-15.00$ \\
\hline CBCL - somatic complaints & 210 & 3.72 & & & $2 \cdot 71$ & $0.00-18.00$ \\
\hline $\mathrm{CBCL}$ - anxious/depressed & 210 & $5 \cdot 86$ & & & 4.00 & $0.00-20.00$ \\
\hline CES-D - total score & 206 & 7.92 & & & $4 \cdot 16$ & $0.00-23.0$ \\
\hline
\end{tabular}

DHA, DHA; GSD, geometric SD; SES, socio-economic status; PC, primary caregiver, CBCL, Child Behavior Checklist ${ }^{(40)}$; CES-D, Center for Epidemiological Studies Depression Scale ${ }^{(41)}$

${ }^{*}$ Assessed on the Hollingshead Index, which represents a weighted score of parental occupation (type of work) and education level(42).

tPersons per room ratio.

†Instrument obtained from First Nations Regional Health Survey, Youth Questionnaire, 2009.

$\S$ Score based on three items adapted from USDA Food security Survey Module(34).

||Adapted version (eight-item instrument) from 2000 USDA Food security Survey Module ${ }^{(34)}$ 
Table 2 Pearson correlation coefficients and $P$ values between adolescent psychological distress scales

\begin{tabular}{|c|c|c|c|c|c|c|c|c|c|}
\hline & $\begin{array}{l}\text { Internalising } \\
\text { behaviours }\end{array}$ & $P$ & $\begin{array}{c}\text { Anxious/ } \\
\text { depressed }^{*}\end{array}$ & $P$ & $\begin{array}{l}\text { Withdrawn/ } \\
\text { depressed* }^{*}\end{array}$ & $P$ & $\begin{array}{c}\text { Somatic } \\
\text { complaints* }\end{array}$ & $P$ & $\begin{array}{l}\text { Depression } \\
\text { scale† }\end{array}$ \\
\hline $\begin{array}{l}\text { Internalising } \\
\text { behaviours* }\end{array}$ & 1 & & & & & & & & \\
\hline $\begin{array}{l}\text { Anxious/ } \\
\quad \text { depressed }^{*}\end{array}$ & 0.898 & $<0.0001$ & 1 & & & & & & \\
\hline $\begin{array}{l}\text { Withdrawn/ } \\
\text { depressed }^{*}\end{array}$ & 0.833 & $<0.0001$ & 0.675 & $<0.0001$ & 1 & & & & \\
\hline $\begin{array}{l}\text { Somatic } \\
\text { symptoms* }\end{array}$ & 0.696 & $<0.0001$ & 0.434 & $<0.0001$ & 0.352 & $<0.0001$ & 1 & & \\
\hline $\begin{array}{l}\text { Depression } \\
\text { scale† }\end{array}$ & 0.556 & $<0.0001$ & 0.524 & $<0.0001$ & 0.486 & $<0.0001$ & 0.308 & $<0.0001$ & 1 \\
\hline
\end{tabular}

${ }^{\star}$ From the Child Behavior Checklist ${ }^{(40)}$.

†Measured by the Center for Epidemiological Studies Depression Scale ${ }^{(41)}$.

Table 3 Beta coefficients of household food insecurity association with psychological distress scores at adolescence, Nunavik, Canada*

\begin{tabular}{|c|c|c|c|c|c|c|c|c|c|}
\hline & \multirow[b]{2}{*}{ Food security } & \multicolumn{4}{|c|}{ Moderate insecurity $v$. security $\dagger$} & \multicolumn{4}{|c|}{ Severe insecurity $v$. security $\dagger$} \\
\hline & & $\beta$ & $\beta_{\text {stand }}$ & SE & $P$ & $\beta$ & $\beta_{\text {stand }}$ & SE & $P$ \\
\hline \multicolumn{10}{|c|}{$\mathrm{CBCL}$ - internalising } \\
\hline Model 1‡ & Reference & 1.78 & $0 \cdot 11$ & 1.52 & 0.24 & 3.39 & 0.21 & 1.54 & 0.03 \\
\hline Model $2 \S$ & Reference & 1.58 & $0 \cdot 10$ & 1.51 & 0.30 & $2 \cdot 85$ & 0.17 & 1.56 & 0.07 \\
\hline \multicolumn{10}{|c|}{ CBCL - anxious/depressed } \\
\hline Model $1 \ddagger$ & Reference & 0.31 & 0.04 & 0.76 & 0.69 & 1.45 & $0 \cdot 18$ & 0.78 & 0.06 \\
\hline Model $2 \S$ & Reference & 0.28 & 0.03 & 0.77 & 0.72 & 1.42 & $0 \cdot 17$ & 0.78 & 0.07 \\
\hline \multicolumn{10}{|c|}{ CBCL - withdrawn/depressed } \\
\hline Model $1 \ddagger$ & Reference & 0.82 & $0 \cdot 14$ & 0.60 & 0.15 & $1 \cdot 60$ & 0.26 & 0.58 & 0.006 \\
\hline Model $2 \S$ & Reference & 0.65 & $0 \cdot 11$ & 0.57 & 0.26 & 1.24 & 0.20 & 0.60 & 0.04 \\
\hline \multicolumn{10}{|c|}{ CBCL - somatic complaints } \\
\hline Model $1 \ddagger$ & Reference & 0.57 & $0 \cdot 10$ & 0.52 & 0.28 & 0.25 & 0.04 & 0.54 & 0.64 \\
\hline Model $2 \S$ & Reference & 0.51 & 0.09 & 0.52 & 0.33 & $0 \cdot 17$ & 0.03 & 0.54 & 0.75 \\
\hline \multicolumn{10}{|c|}{ CES-D - total score } \\
\hline Model $1 \ddagger$ & Reference & 1.37 & $0 \cdot 16$ & 0.80 & 0.09 & 2.53 & 0.30 & 0.81 & 0.002 \\
\hline Model $2 \S$ & Reference & $1 \cdot 17$ & 0.15 & 0.80 & $0 \cdot 14$ & $2 \cdot 24$ & 0.26 & 0.83 & 0.01 \\
\hline
\end{tabular}

CBCL, Child Behavior Checklist ${ }^{(40)}$; CES-D, Center for Epidemiological Studies Depression Scale ${ }^{(41)}$.

${ }^{*} N$ 212; $R^{2}(0.05-0.16)$.

†Categorical score: score comparing moderately food insecure and severely food insecure participants to food secure participants based on a eight-item instrument adapted version from 2000 USDA Food security Survey Module ${ }^{(34)}$.

$\ddagger$ Adjusted for adolescent age and sex.

$\S$ Adjusted for adolescent age and sex, SES score (principal provider) assessed on the Hollingshead Index ${ }^{(42)}$, adolescent perception of household crowding, adolescent having a living child, adolescent tobacco smoking and cord blood DHA.

\section{Discussion}

This was the first study to investigate associations between food insecurity and psychological distress in Inuit adolescents. Food insecurity was common, with about four of ten adolescents experiencing severe food insecurity. Higher food insecurity in adolescence was associated with specific concurrent symptoms of distress: depression and withdrawn attitude. We also found longitudinal associations of persistent food insecurity in childhood through adolescence with depression and anxiety symptoms at adolescence.

In Inuit communities, almost $15 \%$ of adolescents and young adults (15-29 years of age) suffer from psychological distress, and according to a 2012 report, the suicide rate in children and adolescents is thirty times greater than in the general Canadian population ${ }^{(43,44)}$. Several risk factors have previously been associated with distress, such as substance use and interpersonal violence ${ }^{(43)}$. This study suggests that food insecurity is an important risk factor that contributes to psychological distress and that improving food security could be an effective means of reducing distress in a significant portion of the Inuit population.

Food insecurity was associated with concurrent adolescent internalising behaviours, with the strongest association being depression symptoms. These findings are consistent with previous studies which found that children and adolescents living with food insecurity are more likely to suffer from mental health issues, including depressive symptoms and anxiety ${ }^{(19,20,45)}$. A recent review highlighted consistent bivariate relations of food insecurity with behavioural and emotional problems in children and adolescents $^{(17)}$. We found a significant association between food insecure households and the withdrawn/depressed 
Table 4 Beta coefficients of household food insecurity from childhood to adolescence association with psychological distress scores at adolescence, Nunavik, Canada*

\begin{tabular}{|c|c|c|c|c|c|c|c|c|c|c|c|c|}
\hline & \multicolumn{4}{|c|}{$\begin{array}{c}\text { Pattern 1: Childhood food } \\
\text { security to adolescence food } \\
\text { insecurity }(n 26) \text { v. persistent } \\
\text { security }(n \text { 77) } \dagger\end{array}$} & \multicolumn{4}{|c|}{$\begin{array}{c}\text { Pattern 2: Childhood food } \\
\text { insecurity to adolescence food } \\
\text { security }(n \text { 48) v. persistent } \\
\text { security }(n 77) \dagger\end{array}$} & \multicolumn{4}{|c|}{$\begin{array}{c}\text { Pattern 3: Persistent food } \\
\text { insecurity }(n \text { 48) v. persistent } \\
\text { security }(n \text { 77) } \dagger\end{array}$} \\
\hline & $\beta$ & $\beta_{\text {stand }}$ & SE & $P$ & $\beta$ & $\beta_{\text {stand }}$ & SE & $P$ & $\beta$ & $\beta_{\text {stand }}$ & SE & $P$ \\
\hline \multicolumn{13}{|c|}{$\mathrm{CBCL}$ - internalising } \\
\hline Model 1 & 1.50 & 0.08 & 1.40 & 0.29 & 1.49 & 0.06 & 1.73 & 0.39 & 3.52 & 0.19 & 1.40 & 0.01 \\
\hline Model 2 & 0.63 & 0.03 & 1.45 & 0.66 & 1.08 & 0.05 & 1.70 & 0.53 & $2 \cdot 33$ & 0.12 & 1.41 & $0 \cdot 10$ \\
\hline \multicolumn{13}{|c|}{ CBCL - anxious/depressed } \\
\hline Model 1 & 0.56 & 0.06 & 0.70 & 0.43 & 1.04 & 0.09 & 0.87 & 0.23 & 1.61 & 0.17 & $2 \cdot 30$ & 0.02 \\
\hline Model 2 & 0.37 & 0.04 & 0.75 & 0.62 & 0.93 & 0.08 & 0.88 & 0.29 & 1.58 & 0.17 & 0.74 & 0.03 \\
\hline \multicolumn{13}{|c|}{$\mathrm{CBCL}$ - withdrawn /depressed } \\
\hline Model 1 & 0.76 & 0.11 & 1.45 & 0.15 & 1.30 & 0.14 & 0.65 & 0.05 & 1.45 & 0.20 & 0.53 & 0.006 \\
\hline Model 2 & 0.48 & 0.07 & 0.54 & 0.37 & 1.02 & 0.11 & 0.63 & 0.11 & 0.97 & 0.14 & 0.53 & 0.07 \\
\hline \multicolumn{13}{|c|}{ CBCL - somatic complaints } \\
\hline Model 1 & 0.78 & 0.03 & 0.48 & 0.71 & -0.86 & -0.11 & 0.59 & 0.15 & 0.42 & 0.07 & 0.48 & 0.38 \\
\hline Model 2 & $-0 \cdot 12$ & -0.02 & 0.50 & 0.82 & -0.83 & $-0 \cdot 10$ & 0.59 & 0.16 & 0.18 & 0.03 & 0.49 & 0.72 \\
\hline \multicolumn{13}{|c|}{ CES-D - total score } \\
\hline Model 1 & 0.69 & 0.07 & 0.74 & 0.35 & 1.49 & 0.12 & 0.92 & $0 \cdot 10$ & $2 \cdot 10$ & 0.22 & 0.74 & 0.005 \\
\hline Model 2 & 0.28 & 0.03 & 0.76 & 0.71 & 1.19 & 0.10 & 0.91 & 0.19 & 1.73 & 0.18 & 0.75 & 0.02 \\
\hline
\end{tabular}

CBCL, Child Behavior Checklist ${ }^{(40)}$; CES-D, Center for Epidemiological Studies Depression Scale ${ }^{(41)}$.

${ }^{*} N$ 212; $R^{2}(0.05-0.19)$. Model 1 adjusted for adolescent age and sex. Model 2 adjusted for adolescent age and sex, cord blood Pb, parity of the mother, cord blood DHA, childhood house crowding, maternal evaluation of child's health, marital status at childhood follow-up, child blood Pb and $\mathrm{Hg}$, SES score (principal provider) assessed on the Hollingshead Index ${ }^{(42)}$, adolescent perception of house crowding, adolescent having a living child, adolescent tobacco smoking and self-perceived general health.

†Using score based on three items adapted from USDA Food security Survey Module at childhood and eight-item instrument adapted version from 2000 USDA Food security Survey Module at adolescence ${ }^{(34)}$.

and CES-D score, but only for the severe insecurity group, which suggests a non-linear relation between food insecurity and psychological distress

Following the concurrent analyses, we examined food insecurity as a pattern from childhood to adolescence, with the aim of examining whether continuity or change in status would better characterise the long-term association with psychological distress in adolescence. We found that continuity in food insecurity from childhood to adolescence was associated with anxiety and depression. The magnitude of the associations was similar in concurrent and longitudinal measurements. These results corroborate those of previous studies conducted in the general population. Longitudinal associations between food insecurity and psychological distress have been previously observed, with food insecurity in childhood being linked to outcomes such as emotional problems, suicide ideation and depression in late childhood ${ }^{(18,46,47)}$ and in adolescence ${ }^{(21,48,49)}$. Our results also indicated that unstable patterns, meaning being food insecure at one time and food secure at the other, were not related to any internalising problem outcome in adolescence. Thus, only food insecurity status at both childhood and adolescence was linked with emotional disorder symptoms in this population. This association could be driven by the concurrent association between food insecurity and psychological distress at the adolescent assessment. However, if this were the case, we would expect a significant association between all patterns ending with food insecurity in adolescence and the outcomes, which is not what we observed: the pattern from food security in childhood to food insecurity in adolescence was not related to psychological distress in our study. Furthermore, this analysis thus suggests that psychological distress in adolescence is associated with long-term patterns of food insecurity, which limits the risk of reverse causation, that is, psychological distress influencing the perception of greater food insecurity. Nonetheless, there was no association between childhood food insecurity and adolescent internalising behaviours. However, the sample size of the combination of food secure/food insecure from childhood to adolescent was small ( $n$ 26). These longitudinal associations thus need to be examined in future studies in this population.

Initiatives are already in place in Nunavik to improve food security, such as community kitchens and freezer, cooking activities with youth (in school and after school) and breakfast and healthy snacks in school, the valuing of country food and in-store nutrition programmes. These approaches also correspond to protective factors for mental health and well-being identified by young Inuit: being on the land, connection to Inuit culture, strong communities, relationship with family and friends and staying busy ${ }^{(3)}$. Programmes targeted at children, such as distribution of breakfast and healthy snacks at school, also help prevent food insecurity ${ }^{(50)}$. However, it has been reported that food insecurity could affect adolescents even more than children ${ }^{(51)}$. The present study therefore emphasises the importance of continuing and expanding food security-related initiatives, particularly the need to target adolescents as well as including them in the development of dedicated culturally appropriate activities and workshops. 


\section{Strengths}

Among the strengths of this study is the longitudinal design over three assessment periods. This allowed for measurement of food insecurity during both childhood and adolescence and enabled us to include a large number of potential confounding variables to take into account multiple aspects of the social and environmental background of adolescents. In addition, the instruments used to assess the depression and anxiety outcomes had been validated in other populations, and internal consistency measured for this specific population was found to be adequate. The sample involved in this study, Inuit adolescents, represents a vulnerable group for whom few data are available, which makes the present results quite unique. Another major strength is the novelty of the results and their importance for public health in Nunavik since psychological distress in Inuit adolescents is highly prevalent, even though its determinants remain under-investigated.

\section{Limitations}

The sample size prevented us from testing interactions to document whether there are sex differences in the associations reported. Another limitation was that the household food insecurity assessment tools used in the longitudinal analysis were not the same in childhood and adolescence, which could have resulted in misclassification and affected the results obtained. While based on validated questions, some modifications were made so the food insecurity assessment tools used in this study would be applicable to the situation of our participants. These modified tools have therefore not been validated. Since the childhood and adolescent follow-ups took place several years apart, the analysis did not factor in the fluctuations in the household food insecurity that could have occurred between these two times; thus, the persistence of food security or insecurity throughout this period cannot be entirely accounted for. Over-adjustment may be a concern for model 2 analyses as we observed only a small change in beta coefficients from model 1 analyses, which were only adjusted for sex and age of the participant. In particular, model 2 analyses were adjusted for SES, which is correlated with food insecurity. The significant associations found in model 2 analyses show that the relation between food insecurity and psychological distress goes beyond that of SES. Conversely, there might be residual confounding in the analyses because we were not able to adjust for potentially relevant factors, such as family violence and traumatic events.

\section{Conclusion}

Findings from our study are the first to show that food insecurity is associated with psychological distress in Nunavik adolescents. Consistent evidence has shown that child or adolescent food insecurity is associated with anxiety and depression both concurrently and long-term. Given that young people in Inuit communities experience particularly high rates of psychological distress, our findings highlight a modifiable risk factor that could be targeted in prevention programmes and interventions for high-risk youth and their families. Further investigation should focus on repeated measures of food insecurity between childhood and adolescence to evaluate associations between chronicity in food insecurity and psychological distress. From a public health perspective, initiatives to reduce food insecurity actively involving Inuit adolescents warrant consideration. Governmental policies and programmes address the root causes of food insecurity, such as low income and the high cost of living in the region, especially the high cost of food that can represent twice the price in other areas of the province.

\section{Acknowledgements}

Acknowledgements: The authors gratefully thank the Nunavik population, all the people involved in this study and the Nunavik Nutrition and Health Committee for their useful comments on this article. Financial support: This longitudinal research was funded by the Institute of Indigenous People's Health from the Canadian Institutes of Health Research (NRF 130242), US National Institutes of Health/National Institute of Environmental Health Sciences (R01-ES007902); the Northern Contaminants Program from Government Canada; the Lycaki-Young Fund from the State of Michigan. None of the funding programmes and institutes had a role in the design, analysis or writing of this article. Conflict of interest: The authors declare they have no actual or potential competing financial interests. Authorship: M.B.-L.: developing the analysis plan, performing data analysis, interpretation of data, primarily responsible for writing the article under the supervision of G.M., Y.C., M.D.-C., N.F.-D.: contribution in analysis plan, analysis and interpretation of data, article revision. P.A., J.L.J., S.W.J. and G.M.: Principal investigator (PI) and co-PIs of the longitudinal study since its conception, contribution in designing and carrying out the study, interpretation of data and article revision. R.E.B.: co-PI of the adolescence follow-up of the study, contribution in designing and carrying out the adolescence follow-up, interpretation of data and article revision. Ethics of human subject participation: This study was conducted according to the guidelines laid down in the Declaration of Helsinki, and all procedures involving research study participants were approved by the Université Laval and Wayne State University ethics committees (prenatal and NCDSchildhood collections) and the Centre de Recherche du CHU de Québec-Université Laval ethics committee 
(NCDS-adolescence collection). Written informed consent was obtained from all participants in the study.

\section{Supplementary material}

For supplementary material accompanying this paper visit https://doi.org/10.1017/S1368980020000117

\section{References}

1. World Food Summit (1996) Rome Declaration on World Food Security. http://www.fao.org/3/w3613e/w3613e00. htm (accessed May 2020).

2. Arriagada P (2017) Insights on Canadian Society: Food Insecurity among Inuit Living in Inuit Nunangat. Ottawa, Canada: Statistics Canada.

3. Petrasek MacDonald J, Cunsolo Willox A, Ford JD et al. (2015) Protective factors for mental health and well-being in a changing climate: perspectives from Inuit youth in Nunatsiavut, Labrador. Soc Sci Med 141, 133-141.

4. Lemire M, Kwan M, Laouan-Sidi AE et al. (2015) Local country food sources of methylmercury, selenium and omega-3 fatty acids in Nunavik, Northern Quebec. Sci Total Environ 509-510, 248-259. doi: 10.1016/j.scitotenv.2014.07.102.

5. Kuhnlein HV, Receveur O, Soueida R et al. (2004) Arctic indigenous peoples experience the nutrition transition with changing dietary patterns and obesity. $J$ Nutr $\mathbf{1 2 4}$, 1447-1453.

6. Sheikh N, Egeland GM, Johnson-Down L et al. (2011) Changing dietary patterns and body mass index over time in Canadian Inuit communities. Int J Circumpolar Health 70, 511-519.

7. Robitaille J, Guénard E \& Duhaime G (2018) The Cost of Living in Nunavik in 2016. Québec, Canada: Canada Research Chair on Comparative Aboriginal Conditions.

8. Inuit Tapiriit Kanatami (2018) Inuit Statistical Profile 2018. Ottawa, Canada: ITK.

9. Chan HM, Fediuk K, Hamilton S et al. (2006) Food security in Nunavut, Canada: barriers and recommendations. Int $J$ Circumpolar Health 65, 416-431.

10. Pirkle CM, Lucas M, Dallaire R et al. (2014) Food insecurity and nutritional biomarkers in relation to stature in Inuit children from Nunavik. Can J Public Heal 105, e233-e238.

11. Egeland GM, Williamson-Bathory L, Johnson-Down L et al. (2011) Traditional food and monetary access to market-food: correlates of food insecurity among Inuit preschoolers. Int J Circumpolar Health 70, 373-383.

12. Egeland GM, Pacey A, Cao Z et al. (2010) Food insecurity among Inuit preschoolers: Nunavut Inuit child health survey, 2007-2008. CMAJ 182, 243-248.

13. Huet C, Rosol R \& Egeland GM (2012) The prevalence of food insecurity is high and the diet quality poor in Inuit communities. J Nutr 142, 541-547.

14. Gunderson C \& Ziliak JP (2015) Food insecurity and health outcomes. Health Aff 34, 1830-1839.

15. Kursmark M \& Weitzman M (2009) Recent findings concerning childhood food insecurity. Curr Opin Clin Nutr Metab Care 12, 310-316.

16. Liu J, Chen X \& Lewis G (2011) Childhood internalizing behaviour: analysis and implications. J Psychiatr Ment Heal Nurs 18, 884-894.

17. Shankar P, Chung R \& Frank DA (2017) Association of food insecurity with children's behavioral, emotional, and academic outcomes: a systematic review. J Dev Behav Pediatr 38, 135-150.

18. Slopen N, Fitzmaurice G, Williams DR et al. (2010) Poverty, food insecurity, and the behavior for childhood internalizing and externalizing disorders. I Am Acad Child Adolesc Psychiatry 49, 444-452.

19. McLaughlin KA, Green JG, Alegría M et al. (2012) Food insecurity and mental disorders in a national sample of U.S. adolescents. J Am Acad Child Adolesc Psychiatry 51, 1293-1303.

20. Poole-Di Salvo E, Silver EJ \& Stein REK (2016) Household food insecurity and mental health problems among adolescents: what do parents report? Acad Pediatr 16, 90-96.

21. Whitsett D, Sherman MF \& Kotchick BA (2019) Household food insecurity in early adolescence and risk of subsequent behavior problems: does a connection persist over time? J Pediatr Psychol 44, 478-489.

22. Smith K \& Li S (2016) Inuit: Fact Sheet for Nunavik. Ottawa, Canada: Statistics Canada.

23. Chachamovich E, Kirmayer LJ, Haggarty JM et al. (2015) Suicide among Inuit: results from a large, epidemiologically representative follow-back study in Nunavut. Can $J$ Psychiatry 60, 268-275.

24. Dewailly E, Bruneau S, Ayotte P et al. (1993) Health status at birth of Inuit newborn prenatally exposed to organochlorines. Chemosphere 27, 359-366.

25. Jacobson JL, Jacobson SW, Muckle G et al. (2008) Beneficial effects of a polyunsaturated fatty acid on infant development: evidence from the Inuit of Arctic Quebec. J Pediatr 152, 356-364.

26. Muckle G, Ayotte P, Dewailly E et al. (2001) Prenatal exposure of the Northern Quebec Inuit infants to environmental contaminants. Environ Health Perspect 109, 1291-1299.

27. Jacobson JL, Muckle G, Ayotte P et al. (2015) Relation of prenatal methylmercury exposure from environmental sources to childhood IQ. Environ Health Perspect 123, 827-833.

28. Dallaire R, Dewailly É, Ayotte P et al. (2014) Growth in Inuit children exposed to polychlorinated biphenyls and lead during fetal development and childhood. Environ Res 134, $17-23$.

29. Achenbach TM \& Rescorla LA (2001) Manual for the ASEBA School-Age Forms \& Profiles. Burlington, VT: University of Vermont, Research Centre for Children, Youth, \& Families.

30. Achenbach TM, Becker A, Dopfner M et al. (2008) Multicultural assessment of child and adolescent psychopathology with ASEBA and SDQ instruments: research findings, applications, and future directions.J Child Psychol Psychiatry 49, 251-275.

31. Lehti V, Niemela S, Hoven C et al. (2009) Mental health, substance use and suicidal behaviour among young indigenous people in the Arctic : a systematic review. Soc Sci Med 69, 1194-1203.

32. Radloff LS (1977) The CES-D scale: a self-report depression scale for research in the general population. Appl Psychol Meas 1, 385-401.

33. Armenta BE, Hartshorn KJS, Whitbeck LB et al. (2014) A longitudinal examination of the measurement properties and predictive utility of the Center for Epidemiologic studies depression scale among North American indigenous adolescents. Psychol Assess 26, 1347-1355.

34. Bickel G, Nord M, Price C et al. (2000) Guide to Measuring Household Food Security, Revised 2000. Alexandria, VA: United States Department of Agriculture.

35. Indian and Northern Affairs (2003) Nutrition and food security in Kugaaruk, Nunavut : baseline survey for the Food Mail Pilot Project. 130. Ottawa, ON, Canada: Government of Canada. 
36. Office of Nutrition Policy and Promotion Health Products and Food Brand (2007) Canadian Community Health Survey, Cycle 2.2, Nutrition (2004) - income-related household food security in Canada. Ottawa, Ontario: Health Canada.

37. Rothman KJ, Greenland S \& Lash TL (2008) Modern Epidemiology, 3rd ed. Philadelphia: Lippincott Williams \& Wilkins.

38. Little RJA (1988) A test of missing completely at random for multivariate data with missing values. J Am Stat Assoc $\mathbf{8 3}$ 1198-1202.

39. Asparouhov T \& Muthén B (2010) Weighted Least Squares Estimation With Missing Data. Los Angeles: Muthén \& Muthén.

40. Lacalle M, Ezpeleta L \& Doménech JM (2012) DSM-oriented scales of the child behavior checklist and youth self-report in clinically referred Spanish children. Span J Psychol 15, 377-387.

41. Björgvinsson T, Kertz SJ, Bigda-Peyton JS et al. (2013) Psychometric properties of the CES-D-10 in a psychiatric sample. Assessment 20, 429-436.

42. Hollingshead A (2011) Four factor index of social status. Yale J Sociol 8, 21-51.

43. Kirmayer LJ \& Paul K (2007) Qanuippitaa? How Are We? Mental Health, Social Support and Community Wellness. Québec, Canada: Institut National de Santé Publique du Québec.
44. Oliver LN, Peters PA \& Kohen DE (2012) Mortality rates among children and teenagers living in Inuit Nunangat, 1994 to 2008. Heal Reports 23, 1-6.

45. Weinreb L, Wehler C, Perloff J et al. (2002) Hunger: its impact on children's health and mental health. Pediatrics 110, e41-e41.

46. Belsky DW, Moffitt TE, Arseneault L et al. (2010) Context and sequelae of food insecurity in children's development. $\mathrm{Am} \mathrm{J}$ Epidemiol 172, 809-818.

47. Slack KS \& YoO J (2005) Food hardship and child behavior problems among low-income children. Soc Serv Rev 79, 511-536.

48. McIntyre L, Williams JVA, Lavorato DH et al. (2013) Depression and suicide ideation in late adolescence and early adulthood are an outcome of child hunger. $J$ Affect Disord 150, 123-129.

49. Chilton M (2014) Cohort study: child hunger is a prescription for depression in late adolescence and early adulthood. Evid Based Med 19, 113.

50. NRBHSS (2019) Food Security - Nunavik Regional Board of Health and Social Services (NRBHSS). https://nrbhss.ca/en/ departments/public-health/prevention-and-health-promotion/ food-security (accessed May 2020).

51. Moffitt RA \& Ribar DC (2018) Child age and gender differences in food security in a low-income inner-city population. NBER Work Paper no. 22988. 